\title{
Antifungal Activity Toward Fusarium culmorum in Soluble Wheat Extracts
}

\author{
F. M. Doohan, A. Mentewab, and P. Nicholson
}

John Innes Centre, Norwich Research Park, Colney Lane, Norwich NR4 7UH, United Kingdom.

Current address of F. M. Doohan: Department of Environmental Resource Management, Faculty of Agriculture, University College Dublin, Belfield, Dublin 4, Ireland.

Accepted for publication 21 February 2000.

\begin{abstract}
Doohan, F. M., Mentewab, A., and Nicholson, P. 2000. Antifungal activity toward Fusarium culmorum in soluble wheat extracts. Phytopathology 90: 666-671.

This study investigated antifungal activity in soluble extracts from seed of a range of wheat cultivars differing in susceptibility to Fusarium head blight. Antifungal activity was assessed in terms of $\beta$-D-glucuronidase (GUS) activity of a Fusarium culmorum GUS transformant using a sensitive laboratory assay. Significant antifungal activity was detected in seed extracts

from WEK0609, CM 820036, and Arina. Initial characterization of the Arina seed extract indicated that it contained antifungal proteinaceous compounds. The Arina extract yielded two (60 and 80\%) ammonium sulfate fractions containing inhibitory compounds. Gel filtration chromatography and subsequent sodium dodecyl sulfate-polyacrylamide gel electrophoresis of antifungal fractions showed that the antifungal activities detected in the Arina 60 and $80 \%$ ammonium sulfate fractions were associated with putative proteinaceous compounds with apparent molecular masses of approximately 60 and $28 \mathrm{kDa}$, respectively.
\end{abstract}

Antifungal proteins have been identified in several small grain cereals including wheat $(5,35)$. Such antimicrobial defense compounds may be constitutively expressed by host plants or induced following microbial attack $(6,9,14)$. Biochemical studies have revealed that plant antimicrobial defense compounds including chitinases, permatins, 1,3- $\beta$-glucanases, and ribosome-inactivating proteins (RIPs) are present in seed from a range of different cereals $(5,23-27,35,36)$. Darnetty et al. (5) showed that these compounds were all present in small grain cereals and that there was isozymic variability in the antifungal proteins detected in maize, sorghum, and wheat. Biochemical studies have identified proteins that have been associated with host pathogen resistance. Studies of maize seed have identified antifungal proteins that have been correlated with resistance to Aspergillus flavus $(4,11)$. Two fractions were isolated from seed of an aflatoxin accumulation-resistant corn cultivar, one that inhibited growth of A. flavus and another that inhibited aflatoxin accumulation (11).

Several Fusarium species including F. culmorum and F. graminearum are important pathogens of wheat causing seedling blight, foot rot, and head blight (FHB) (also known as ear blight or "scab") (20). These pathogens also have the potential to produce mycotoxins (e.g., deoxynivalenol [DON], T-2 toxin, and zearalenone) in grains that are harmful to both human and animal health (13, 15,33). To date, there have been few reports of investigations to identify the biochemical factors that might be involved in resistance to FHB. Studies on the genetics of FHB resistance showed that wheat resistance to $F$. graminearum and $F$. culmorum appears to share a common genetic background $(16,31)$. Schroeder and Christensen (28) postulated that there were two mechanisms of FHB resistance (type I and type II) that varied independently among cultivars. Type I resistance operates against initial infection and type II against spread of the pathogen within the host. Other workers proposed that the host response to DON formed the basis for the determination of two further types of resistance (type III and type IV), having the same phenotype as type II resistance. Type III

Corresponding author: F. M. Doohan; E-mail address: fiona.doohan@ucd.ie

Publication no. P-2000-0411-01R

(C) 2000 The American Phytopathological Society resistance is the ability of the host plant to degrade DON (18) and type IV is the tolerance of high DON concentrations (37).

The objective of the current study was to examine FHB-resistant and FHB-susceptible wheat cultivars for the presence of antifungal compounds in soluble extracts from grain using an in vitro bioassay. We also report the initial characterization of antifungal compounds from seed extracts of the FHB-resistant cultivar Arina.

\section{MATERIALS AND METHODS}

Plant material. The wheat cultivars used in this study included FHB-susceptible and FHB-resistant winter and spring wheat cultivars. The FHB-susceptible winter wheat cultivars used were Riband and Hobbit 'sib' (syn. Dwarf A) (2,8; N. Gosman, personal communication), and the FHB-resistant winter wheat cultivars used were Triticum macha, Pioneer WEK0609, and Arina (2,8,32; N. Gosman, personal communication). The FHB-susceptible spring wheat cultivars used were Remus, Timstein, and Chinese Spring (2, 3 ), and the FHB-resistant spring wheat cultivars used were Frontana, Su Mai 3, and CM $82036(3,12,18,32,34)$. Where possible, seed was obtained from plants grown under greenhouse conditions during 1997 to 1998 , and all seed was held at $4^{\circ} \mathrm{C}$ prior to protein extraction.

Fungal material. The $F$. culmorum $\beta$-D-glucuronidase (GUS) transformant G514 used in antifungal assays harbors the GUS gene ( gusA) under the control of the glyceraldehyde-3-phosphate dehydrogenase $(G P D 1)$ promoter (7). Media and conditions used for maintenance and subculturing were as described previously (7). Conidial inoculum was produced by growing G514 on potato dextrose broth (PDB) (Difco Laboratories, Detroit) at $20^{\circ} \mathrm{C}$ for 14 to 24 days. Conidia were harvested using sterile distilled $\mathrm{H}_{2} \mathrm{O}$ and the concentration was adjusted to $10^{6}$ conidia per $\mathrm{ml}$.

Protein extraction. Wheat seeds were coarsely ground in a coffee grinder (Krups, Birmingham, United Kingdom) and milled to a fine powder using a Glen Creston mixer/mill 8000 (Glen Creston, Middlesex, United Kingdom). The powder was incubated in protein extraction buffer $(5 \mathrm{mM} \mathrm{NaPO}, 10 \mathrm{mM} \mathrm{NaCl}$, and $1 \mathrm{mM}$ EDTA, pH 7) at $0.2 \mathrm{~g} \mathrm{ml}^{-1}$ (35) for $3.5 \mathrm{~h}$. The resulting suspension was centrifuged at $15,000 \times g$ for $10 \mathrm{~min}$, and the supernatant was filtered through Whatman No. 1 filter paper (Whatman Interna- 
tional, Ltd., Maidstone, United Kingdom). Extracts were filtersterilized through $0.20-\mu \mathrm{m}$ filters and used immediately or frozen and stored at $-70^{\circ} \mathrm{C}$. Protein concentration was measured using the BioRad protein assay (BioRad Laboratories, Ltd., Hertfordshire, United Kingdom).

Antifungal activity. Extracts were mixed with 10× PDB (1:9 $\mathrm{vol} / \mathrm{vol}$ ) and filter sterilized, after which 1-ml aliquots were placed in 25-well tissue culture plates (Nalge Nunc International, Hereford, United Kingdom). Cultures were inoculated with conidia of F. culmorum (G514) to a final concentration of $1 \times 10^{5}$ conidia per $\mathrm{ml}$ and incubated at $20^{\circ} \mathrm{C}$. After $48 \mathrm{~h}$, fungal mycelia were transferred to 1.5-ml Eppendorf tubes and centrifuged at 15,000 $\times g$ for $10 \mathrm{~min}$, and the supernatant was removed. Tissue culture wells were washed with $1 \mathrm{ml}$ of sterile distilled $\mathrm{H}_{2} \mathrm{O}$ and the wash was added to the appropriate Eppendorf tube. After centrifugation and removal of supernatant (described above), fungal biomass was determined by GUS activity as described previously (7) and expressed as nanomoles methylumbelliferyl per minute per milliliter of fungal culture.

Temperature sensitivity of seed extracts. Aqueous seed extracts were tested for temperature sensitivity by incubation at $99^{\circ} \mathrm{C}$ for $10 \mathrm{~min}$. Following centrifugation at $5,000 \times g$ for 10 min, the supernatants were mixed with PDB and assayed for antifungal activity as described above. Non-heat-treated extracts served as positive controls.

Fractionation of seed extracts. Aqueous extracts from Arina and Riband were subjected to stepwise ammonium sulfate $\left(\left(\mathrm{NH}_{4}\right)_{2} \mathrm{SO}_{4}\right)$ fractionation with $20,40,60,80$, and $100 \%$ saturation, and subsequent dialysis against protein extraction buffer was as described previously (10). The fractions and the supernatant, diluted to $0.1 \mathrm{~g}$ of seed per $\mathrm{ml}$ of protein extraction buffer, were assayed for antifungal activity as described above. To test the potency of the antifungal activities, serial dilutions of these 60 and $80 \%$ fractions were prepared corresponding to $0.1,0.05$, and $0.025 \mathrm{~g}$ of seed per $\mathrm{ml}$ of protein extraction buffer, and these dilutions were tested for antifungal activity.

Proteinase treatment and solubility of antifungal $\left(\mathrm{NH}_{4}\right)_{2} \mathrm{SO}_{4}$ fractions from Arina seed extract. Proteinase treatment was performed by incubating seed extract with proteinase K (Sigma Chemical Co., Dorset, United Kingdom) at 26 units per $\mathrm{ml}$ in $50 \mathrm{mM}$ Tris- $\mathrm{HCl}$ plus $2 \mathrm{mM} \mathrm{CaCl}_{2}\left(\mathrm{pH} \mathrm{7.5)}\right.$ for $1 \mathrm{~h}$ at $37^{\circ} \mathrm{C}$. Extracts (diluted to $0.1 \mathrm{~g}$ of seed per $\mathrm{ml}$ of protein extraction buffer) were tested for antifungal activity as described above. For extracts incubated with active/inactivated proteinase $\mathrm{K}$, growth was expressed relative to the corresponding control (PDB plus active/inactivated proteinase $\mathrm{K}$ ).

The solubility of the antifungal compounds in ethyl acetate, chloroform, and methanol was investigated as described previously (11). Fractions were tested for antifungal activity as described above. PDB minus extract served as a control.

Gel filtration chromatography of antifungal $\left(\mathrm{NH}_{4}\right)_{2} \mathrm{SO}_{4}$ fractions from Arina seed extract. Arina 60 and $80 \%\left(\mathrm{NH}_{4}\right)_{2} \mathrm{SO}_{4}$ pellets were diluted to $0.4 \mathrm{~g}$ of seed per $\mathrm{ml}$ of protein extraction buffer containing $0.15 \mathrm{M} \mathrm{NaCl}$ and were applied to a HiLoad Superdex S-200 gel filtration column (Amersham Pharmacia Biotech, Hertfordshire, United Kingdom) previously preconditioned in this buffer. The column was eluted at a flow rate of $1 \mathrm{ml} \mathrm{min}^{-1}$, protein content was measured by absorbance at $280 \mathrm{~nm}$, and the eluate was collected as 1-ml fractions. For antifungal activity assays, 100- $\mu \mathrm{l}$ aliquots of successive fractions were pooled to $200 \mu \mathrm{l}$, diluted to $2 \mathrm{ml}$ using full strength PDB, and assayed for antifungal activity as described above. PDB minus extract served as a control. This was performed twice for Arina 60 and $80 \%\left(\mathrm{NH}_{4}\right)_{2} \mathrm{SO}_{4}$ fractions, and antifungal fractions were pooled and concentrated to $2 \mathrm{ml}$ using $10 \mathrm{kDa}$ MMCO Centricons (Millipore Ltd., Hertfordshire, United Kingdom) according to the manufacturer's instructions. These concentrates were applied to a HiLoad Superdex S-75 gel filtration column, and the conditions and antifungal activity assays were as described above, except that, for the 60 and $80 \%\left(\mathrm{NH}_{4}\right)_{2} \mathrm{SO}_{4}$ fractions, 50- and 100- $\mu$ l aliquots of successive fractions were pooled and assayed for antifungal activity.
Sodium dodecyl sulfate-polyacrylamide gel electrophoresis (SDS-PAGE). SDS-PAGE was performed on both the 60 and $80 \%\left(\mathrm{NH}_{4}\right)_{2} \mathrm{SO}_{4}$ fractions of Arina and Riband and on the HiLoad Superdex S-75 gel filtration fractions containing antifungal activity. Protogel polyacrylamide gels (10\%; National Diagnostics, Hull, United Kingdom) were prepared according to the manufacturer's recommendations. Nonreduced samples, loaded in a volume of $20 \mu \mathrm{l}$, contained $10 \mu \mathrm{l}$ of $\left(\mathrm{NH}_{4}\right)_{2} \mathrm{SO}_{4}$ fraction or gel filtration eluate, $5 \%$ SDS (wt/vol), $10 \%$ glycerol (vol/vol), and $0.01 \%$ bromophenol blue in $62.5 \mathrm{mM}$ Tris-HCl, $\mathrm{pH}$ 6.8. The Rainbow broad-range ladder (BioRad Laboratories, Ltd.) was used as a molecular mass marker. Gels were run in a Miniprotean II electrophoresis unit (BioRad Laboratories, Ltd.) at $200 \mathrm{~V}(0.1 \%$ SDS, $25 \mathrm{mM}$ Tris, and $192 \mathrm{mM}$ glycine, $\mathrm{pH}$ 8.3) until the bromophenol indicator reached the end of the gel. Gels were stained for $2 \mathrm{~h}$ with $0.025 \%$ Coomassie brilliant blue R-250 (Sigma Chemical Co.) in $0.35 \mathrm{M}$ trichloroacetic acid, $1 \mathrm{M}$ acetic acid, and $18 \%$ ( $\mathrm{vol} / \mathrm{vol}$ ) methanol and destained in $50 \%$ methanol and $10 \%$ acetic acid for 1 to $2 \mathrm{~h}$. The gel filtration SDS-PAGE gels were scanned using a 690 Imaging Densitometer and Molecular Analyst software (BioRad Laboratories, Ltd.) and the intensity of protein bands were measured as described previously (7).

Statistical analysis. Statistical analysis was carried out using analysis of variance and Tukey's pairwise comparison test at the 10.0, 5.0, and 1.0\% levels of significance (Minitab release 10.1; Minitab, Inc., State College, PA). Where necessary, appropriate transformations of results were used in order to approximate normal distributions of the data for statistical analysis (30).

\section{RESULTS}

Antifungal activity in seed extracts. Antifungal activities of seed extracts containing full-strength PDB medium against $F$. culmorum (G514) are shown in Table 1. The results are based on three replicate experiments, expressed both as GUS activity and relative to growth in PDB control medium. Growth of F. culmorum in seed extracts from WEK0609, CM 82036, and Arina was significantly lower $(P<0.01,0.05$, and 0.01 , respectively) than that observed in the PDB control. There was no significant difference between growth in PDB and in any of the other extracts tested. However, compared with Riband extract, significantly less growth $(P<0.01)$ was observed not only in WEK0609, CM 82036, and Arina extracts, but also in Frontana and Su Mai 3 extracts.

TABLE 1. Fusarium head blight (FHB) resistance and fungal growth expressed as $\beta$-D-glucuronidase (GUS) activity in seed extracts of wheat containing potato dextrose broth (PDB) medium

\begin{tabular}{lclc}
\hline & & \multicolumn{2}{c}{ GUS activity } \\
\cline { 3 - 4 } Cultivar & Resistance $^{\mathrm{a}}$ & Non-heat-treated & Heat-treated \\
\hline Riband & $\mathrm{S}$ & $969 \pm 75(112)$ & $1,681 \pm 62(194)$ \\
Hobbit 'sib' & $\mathrm{S}$ & $756 \pm 111(87)$ & $1,657 \pm 59(191)$ \\
Remus & $\mathrm{S}$ & $717 \pm 44(82)$ & $1,906 \pm 226(220)$ \\
Timstein & $\mathrm{S}$ & $666 \pm 73(77)$ & $1,888 \pm 138(218)$ \\
Chinese Spring & $\mathrm{MS}$ & $680 \pm 211(78)$ & $1,423 \pm 31(164)$ \\
Triticum macha & $\mathrm{R}$ & $732 \pm 159(78)$ & $1,574 \pm 152(181)$ \\
Frontana & $\mathrm{R}$ & $587 \pm 289(68)$ & $2,020 \pm 247(232)$ \\
Su Mai 3 & $\mathrm{R}$ & $577 \pm 71(66)$ & $1,686 \pm 232(194)$ \\
WEK0609 & $\mathrm{R}$ & $463 \pm 106(53)^{* *}$ & $1,588 \pm 80(183)$ \\
CM 82036 & $\mathrm{R}$ & $533 \pm 119(61)^{*}$ & $1,717 \pm 309(198)$ \\
Arina & $\mathrm{R}$ & $442 \pm 125(51)^{* *}$ & $1,683 \pm 151(194)$ \\
PDB control & $\ldots$ & $868 \pm 58(100)$ & $\ldots$ \\
\hline
\end{tabular}

a FHB resistance scored as $\mathrm{S}=$ susceptible, $\mathrm{MS}=$ moderately susceptible, and $\mathrm{R}=$ resistant

b Mean GUS activity in extracts (based on three replicate experiments) \pm standard deviation in nanomoles methylumbelliferyl per minute per milliliter of fungal culture. GUS activity relative to that in PDB is given in parentheses. Values significantly lower than PDB at the 1 and 5\% levels are indicated by ** and *, respectively, based on Tukey's pairwise comparison test. 
Temperature sensitivity of seed extracts. The temperature sensitivity of seed extracts, expressed as fungal biomass (absolute GUS activity) detected in heat-treated samples $\left(99^{\circ} \mathrm{C}, 10 \mathrm{~min}\right)$ and expressed relative to the biomass detected in PDB control medium, is shown in Table 1. Following heat treatment, antifungal activity was not detected in any of the 11 extracts relative to growth in either PDB or heat-treated Riband extract $(P>0.1)$.

Ammonium sulfate fractionation of Arina and Riband seed extracts. Since the highest antifungal activity was detected in Arina seed extract, further studies were performed to determine the nature of the inhibitory compound or compounds present. Stepwise $\left(\mathrm{NH}_{4}\right)_{2} \mathrm{SO}_{4}$ fractionation of Arina seed extract was performed to further purify and characterize the antifungal activity detected in these extracts. Riband seed extract was also fractionated and served as a non-antifungal control extract. The results, based on two replicate experiments, were expressed as fungal biomass (GUS activity) relative to that in PDB control medium (Fig. 1). Growth was significantly lower in the 60 and $80 \%$ fractions from both Arina and Riband than those in PDB $(P<0.01)$, but growth in these Arina fractions was also significantly lower than those in the corresponding Riband fractions $(P<0.01$ and 0.05 , respectively). Antifungal assays of serial dilutions of the 60 and $80 \%$ fractions (Fig. 1) showed that antifungal activity was proportional to concentration (data not shown).

Proteinase treatment and solubility of antifungal $\left(\mathrm{NH}_{4}\right)_{2} \mathrm{SO}_{4}$ fractions from Arina. Growth in PDB containing the 60 and $80 \%$ fractions treated with active proteinase $\mathrm{K}$ was not significantly less than that detected in the PDB control medium supplemented with active proteinase $\mathrm{K}(P>0.1)$ (Table 2$)$. However, growth in PDB containing the 60 and $80 \%$ fractions treated with inactivated enzyme was significantly lower than that in PDB control medium supplemented with inactivated proteinase $\mathrm{K}(P<0.01$ and 0.05 , respectively). Growth was less in the PDB control medium containing active proteinase $\mathrm{K}$ than that in PDB containing inactivated enzyme $(P<0.01)$. Compared with previous experiments (Fig. 1$)$, results from the inactivated enzyme treatment showed that antifungal activity appeared to be lost in both the 60 and $80 \%$ fractions due to the incubation step in this assay $\left(37^{\circ} \mathrm{C}\right.$ for $\left.1 \mathrm{~h}\right)$. The inhibitory compound(s) present in these $\left(\mathrm{NH}_{4}\right)_{2} \mathrm{SO}_{4}$ fractions did not partition into either ethyl acetate or chloroform, or the interfaces between these solvents and water, and did not dissolve in methanol (data not shown).

SDS-PAGE analysis of the 60 and $80 \%$ ammonium sulfate fractions of Arina and Riband seed extracts. SDS-PAGE analysis of both the 60 and $80 \%\left(\mathrm{NH}_{4}\right)_{2} \mathrm{SO}_{4}$ fractions was used to detect

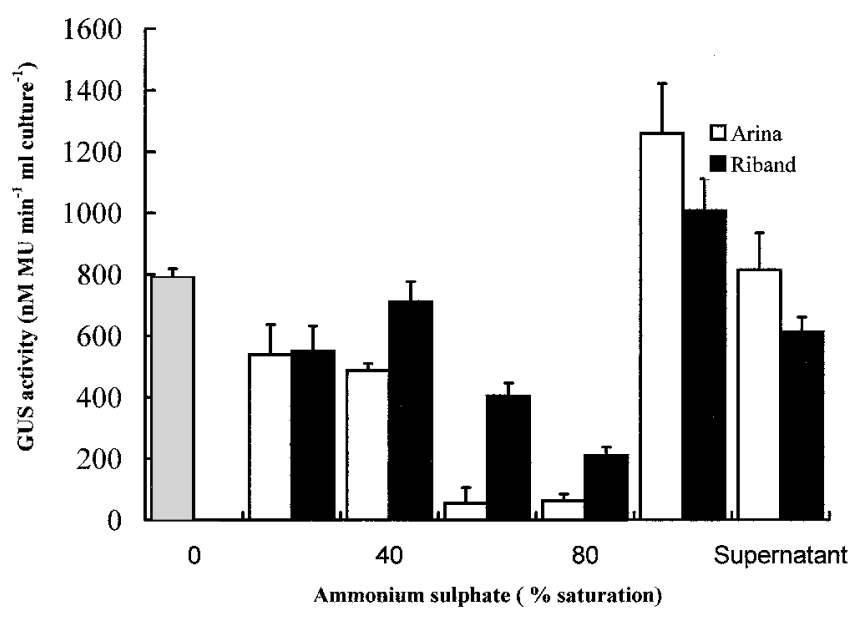

Fig. 1. Growth of Fusarium culmorum (G514) in potato dextrose broth (PDB) containing ammonium sulfate $\left(\left(\mathrm{NH}_{4}\right)_{2} \mathrm{SO}_{4}\right)$ fractions of Arina and Riband seed extracts. Growth was measured as $\beta$-D-glucuronidase (GUS) activity. Bars indicate standard deviation. Gray bar $=$ PDB control. whether any of the proteinaceous bands present in Arina were not present in Riband (Fig. 2). The $80 \%$ Arina fraction contained a proteinaceous compound of approximately $28 \mathrm{kDa}$ that was much more intense than a band of the corresponding size present in Riband (Fig. 2, lanes 3 and 4, respectively). No such differences in the SDS-PAGE protein profiles within the $60 \%$ fractions of Arina and Riband were obvious. However, within the 50- to $75-\mathrm{kDa}$ molecular mass range of the $60 \%$ fractions, the results were difficult to interpret because there were many closely aligned proteinaceous bands in both Arina and Riband (Fig. 2, lanes 1 and 2, respectively).

Gel filtration chromatography and SDS-PAGE analysis of antifungal $\left(\mathrm{NH}_{4}\right)_{2} \mathrm{SO}_{4}$ fractions from Arina seed extract. Gel filtration performed using a broad molecular mass range matrix $(10$ to $600 \mathrm{kDa}$ ) and subsequent assays showed that the antifungal compounds within the 60 and $80 \%\left(\mathrm{NH}_{4}\right)_{2} \mathrm{SO}_{4}$ fractions appeared to be associated with proteinaceous compounds with an apparent molecular mass $<75 \mathrm{kDa}$ (data not shown). Application of these antifungal eluates to a 3- to $75-\mathrm{kDa}$ gel filtration matrix enabled better resolution of the antifungal compounds from both the Arina 60 and $80 \%\left(\mathrm{NH}_{4}\right)_{2} \mathrm{SO}_{4}$ fractions (Figs. 3 and 4, respectively). For the $60 \%$ Arina $\left(\mathrm{NH}_{4}\right)_{2} \mathrm{SO}_{4}$ fraction, compounds eluted 77 to $88 \mathrm{~min}$ after sample application exhibited the greatest antifungal activity. Antifungal activity was also detected in compounds eluted 95 to 96 min after sample application (Fig. 3A). In the case of the $80 \%$ $\left(\mathrm{NH}_{4}\right)_{2} \mathrm{SO}_{4}$ fraction, compounds eluted by gel filtration between 91 and 104 min after sample application exhibited the greatest antifungal activity (Fig. 4A). The $80 \%$ fraction also contained antifungal activity in compounds eluted between 67 and $76 \mathrm{~min}$ and between 83 and 88 min after sample application. When gel filtration eluates from both the $60 \%$ ( $83 \mathrm{~min}$ ) and $80 \%$ (98 $\mathrm{min}$ ) fractions was treated with proteinase $\mathrm{K}$, antifungal activity was no longer detected (data not shown).

SDS-PAGE analysis was used to examine the profiles of nonreduced proteinaceous compounds from the antifungal gel filtration

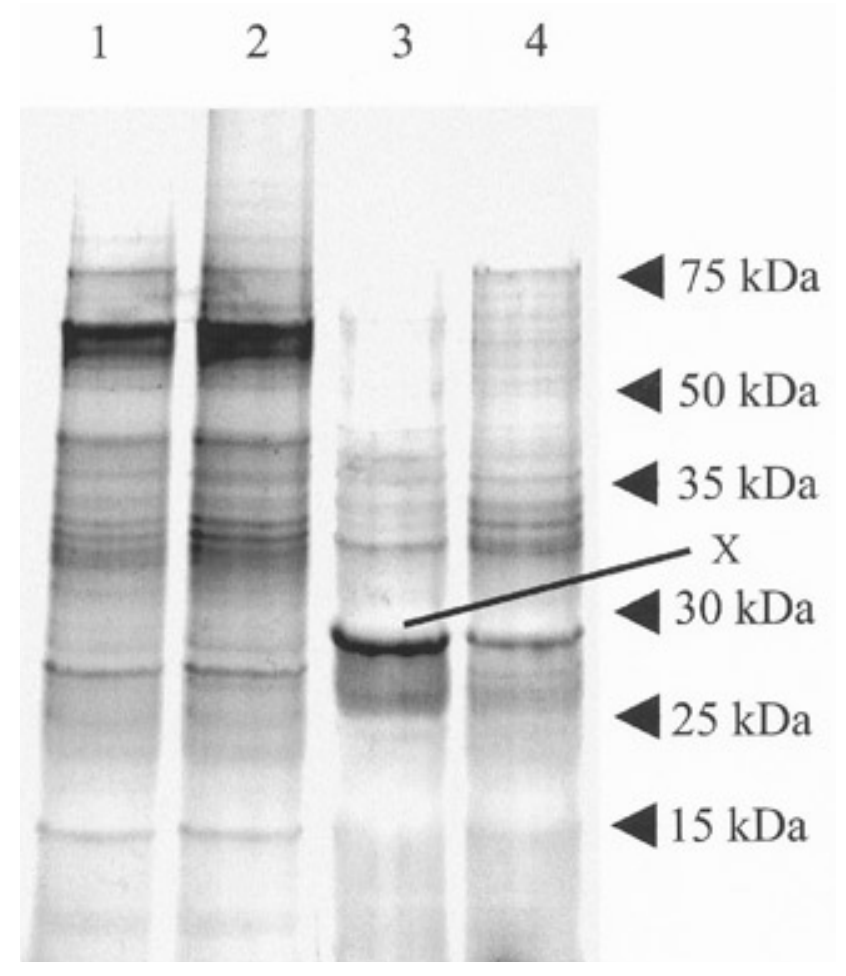

Fig. 2. Sodium dodecyl sulfate-polyacrylamide gel electrophoresis of nonreduced proteinaceous compounds from Arina and Riband ammonium sulfate $\left(\left(\mathrm{NH}_{4}\right)_{2} \mathrm{SO}_{4}\right)$ fractions. Lane 1, 60\% Arina fraction; lane 2, 60\% Riband fraction; lane 3, 80\% Arina fraction; and lane 4, 80\% Riband fraction. Arrows indicate apparent molecular mass markers $(\mathrm{kDa})$ and marker $\mathrm{X}$ indicates position of variability between Arina and Riband in their profiles of proteinaceous compounds. 
eluates of the 60 and $80 \%\left(\mathrm{NH}_{4}\right)_{2} \mathrm{SO}_{4}$ fractions (Figs. 3A and $4 \mathrm{~A}$, respectively). Analysis of the most inhibitory eluates from the $60 \%$ fraction (77 to $88 \mathrm{~min}$ ) showed that antifungal activity was strongly associated with the band intensity of a proteinaceous compound of approximately $60 \mathrm{kDa}(r=0.90)$ (Fig. 3B). Analysis of the most inhibitory eluates from the $80 \%$ fraction (91 to $104 \mathrm{~min}$ ) showed that this antifungal activity appeared strongly associated with a proteinaceous compound of approximately $28-\mathrm{kDa}$ apparent molecular mass $(r=0.96)$ (Fig. 4B). The $60 \%$ fraction also contained a $28-\mathrm{kDa}$ proteinaceous compound in the antifungal eluates collected between 95 and $96 \mathrm{~min}$, and the $80 \%$ fraction contained a $60-\mathrm{kDa}$ proteinaceous compound in the antifungal eluates collected between 83 and $88 \mathrm{~min}$ (data not shown). Both proteinaceous compounds appeared strongly associated with the antifungal activities detected in these eluates $(r=0.80$ and 0.98, respectively). The $80 \%$ fraction contained antifungal eluates collected between 67 and $76 \mathrm{~min}$ in which no protein band correlated with antifungal activity (data not shown).

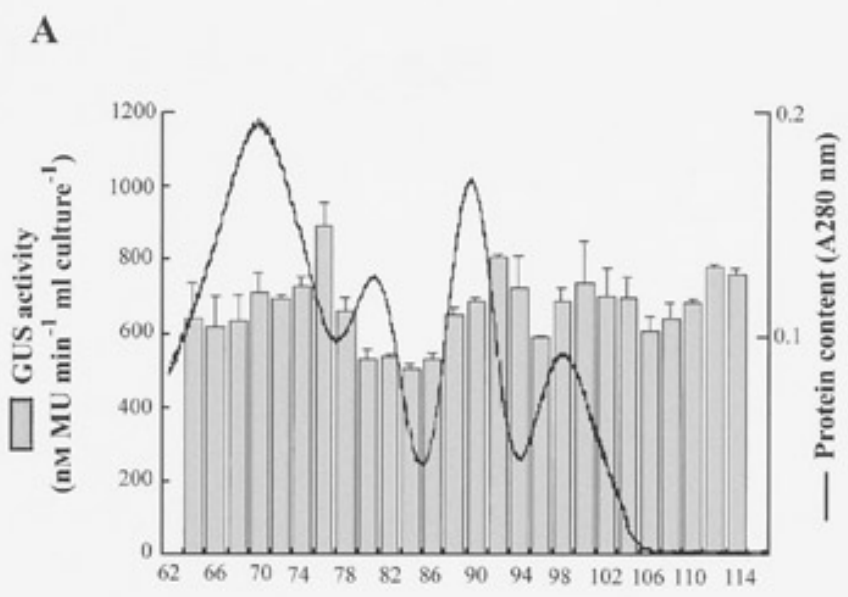

Time after sample application $(\mathrm{min})$

B

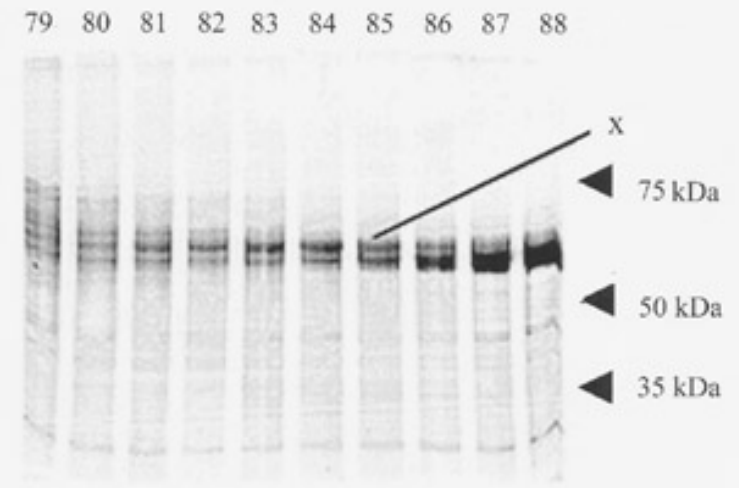

Fig. 3. Gel filtration chromatography ( 3 to $75 \mathrm{kDa}$ ) of the antifungal eluates resulting from $10-$ to $600-\mathrm{kDa}$ gel filtration chromatography of the $60 \%$ $\left(\mathrm{NH}_{4}\right)_{2} \mathrm{SO}_{4}$-saturated fraction from Arina seed extract. A, Gel filtration chromatography and growth of Fusarium culmorum (G514) in potato dextrose broth (PDB) containing the resulting eluates. Protein content was measured by absorbance at $280 \mathrm{~nm}$. Fungal biomass was measured and expressed as mean $\beta$-D-glucuronidase (GUS) activity (PDB $=714 \pm 20 \mathrm{nM}$ methylumbelliferyl $[\mathrm{MU}]$ per min per $\mathrm{ml}$ of culture). Bars indicate standard deviation. B, Sodium dodecyl-sulfate polyacrylamide gel electrophoresis of nonreduced proteinaceous compounds eluted between 79 and 88 min (lanes 79 to 88 , respectively) after sample application. Arrows indicate apparent molecular mass markers $(\mathrm{kDa})$ and marker $\mathrm{X}$ indicates position of a proteinaceous compound strongly associated with antifungal activity $(r=0.90)$.

\section{DISCUSSION}

A number of mechanisms have been proposed for the resistance of wheat to FHB. Resistance to infection (type I) may be due to morphological characters or physical barriers. Similarly, resistance to colonization (type II) may be of a chemical or physical nature. Trichothecene mycotoxins have been shown to be virulence factors for $F$. graminearum (22). The ability to metabolize toxins (type III resistance) or to resist or tolerate toxins (type IV resistance) may contribute to the resistance of some cultivars toward Fusarium spp. $(18,19)$, resulting in a type II phenotype. Resistance of wheat to FHB is, however, most probably due to a number of factors, as evidenced by its polygenic nature in a range of wheat cultivars (17).

In wheat and other small grain cereals, soluble antifungal compounds present in seed have been associated with host resistance to other fungal pathogens $(4,5,23-27,36)$. The current work was undertaken to identify differences in antifungal activity toward $F$. culmorum, presumably due to preformed compounds, in soluble extracts from seed of wheat cultivars differing in their resistance to FHB. The aim of this work was to identify sources of such compounds, to compare seed extract antifungal activity with the FHB susceptibility or resistance of wheat cultivars, and to perform partial characterization of the antifungal compounds present in the seed extract showing the highest antifungal activity. We report on the use of a GUS bioassay that enables sensitive and rapid screening of large numbers of samples for such compounds.

Seed extracts from the FHB-resistant cultivars WEK0609, CM 82036 , and Arina $(2,3,8,29,32)$ possessed significant antifungal activity toward F. culmorum, while those of Frontana, Su Mai 3, Riband, Remus, Timstein, and Chinese Spring did not. Highest antifungal activity was detected in Arina seed extract, a cultivar that has significantly lower in vitro DON tolerance than the Fusarium-resistant cultivars WEK0609, Frontana, and Su Mai 3 (N. Gosman, T. Worland, and P. Nicholson, unpublished data). Neither Frontana nor Su Mai 3 possessed significant antifungal activity in soluble seed extracts. Frontana is reported to metabolize DON (18), and both Frontana and the accession of Su Mai 3 used in the current work have significant in vitro tolerance to DON (3; N. Gosman, T. Worland, and P. Nicholson, unpublished data). Thus, it is conceivable that Fusarium resistance of Arina may be largely due to antifungal activity in the seed, whereas that of Frontana and $\mathrm{Su}$ Mai 3 may be largely due to toxin tolerance or degradation. The resistance of WEK 0609 and CM 82036, both of which demonstrate in vitro tolerance to DON 3 (N. Gosman, T. Worland, and P. Nicholson, unpublished data), may be due to a combination of toxin tolerance and antifungal activity of seed extracts. It is postulated that the role, if any, of antifungal activity in Fusarium resistance of wheat may lie in type II resistance, which, like that of types III and IV, acts against spread of the pathogen within the host. Conformation of these hypotheses must await detailed genetic and biochemical characterization of these cultivars.

In addition to possessing the highest antifungal activity in seed extract, Arina stem base extract supported less fungal growth than did that of Riband (F. M. Doohan, A. Mentewab, and P. Nicholson,

TABLE 2. Effect of proteinase $\mathrm{K}$ treatment on the growth of Fusarium culmorum (G514), expressed as $\beta$-D-glucuronidase (GUS) activity, in both the 60 and $80 \%$ ammonium sulfate $\left(\left(\mathrm{NH}_{4}\right)_{2} \mathrm{SO}_{4}\right)$ fractions of Arina seed extract

\begin{tabular}{lcc}
\hline & \multicolumn{2}{c}{$\left.\mathrm{GUS} \mathrm{NH}_{4}\right)_{2} \mathrm{SO}_{4}$} \\
\cline { 2 - 3 } saturation $(\%)$ & Active proteinase $\mathrm{K}$ & Inactivated proteinase $\mathrm{K}^{\mathrm{a}}$ \\
\hline 60 & $1,066 \pm 168(129)$ & $896 \pm 36(76)$ \\
80 & $877 \pm 65(106)$ & $991 \pm 42(84)$ \\
PDB control & $828 \pm 70(100)$ & $1184 \pm 32(100)$ \\
\hline
\end{tabular}

a Mean GUS activity in extracts (based on three replicate experiments) \pm standard deviation in nanomoles methylumbelliferyl per minute per milliliter of fungal culture. GUS activity relative to that in the corresponding potato dextrose broth (PDB) control medium is given in parentheses. 
unpublished data). Therefore, Arina was chosen for further study to determine the nature of the inhibitory compound(s) in seed extract. The antifungal activity in Arina seed extract was heat-labile, and the greatest antifungal activity occurred in two (60 and 80\%) $\left(\mathrm{NH}_{4}\right)_{2} \mathrm{SO}_{4}$ fractions. Riband also contained antifungal activity in these fractions, but it was significantly less than that detected in Arina.

The inhibitory activities present in these $\left(\mathrm{NH}_{4}\right)_{2} \mathrm{SO}_{4}$ fractions were not detected following proteinase $\mathrm{K}$ treatment, they did not partition into either ethyl acetate or chloroform, and they were insoluble in methanol. These results indicated that Arina seed extract contained antifungal compounds that were proteinaceous in nature. Also, SDS-PAGE analysis of nonreduced proteins from the $80 \%$ fractions showed that an approximately $28-\mathrm{kDa}$ proteinaceous compound present in both Arina and Riband was present in much higher quantities in the former. However, in the $60 \%$ fractions, there were no clear differences between the proteinaceous compounds present in Arina and Riband.

Gel filtration coupled with SDS-PAGE analysis of nonreduced proteins enabled association of the antifungal activity detected in Arina seed extract with two proteinaceous compounds with apparent molecular masses of approximately 28 and $60 \mathrm{kDa}$. If antifungal

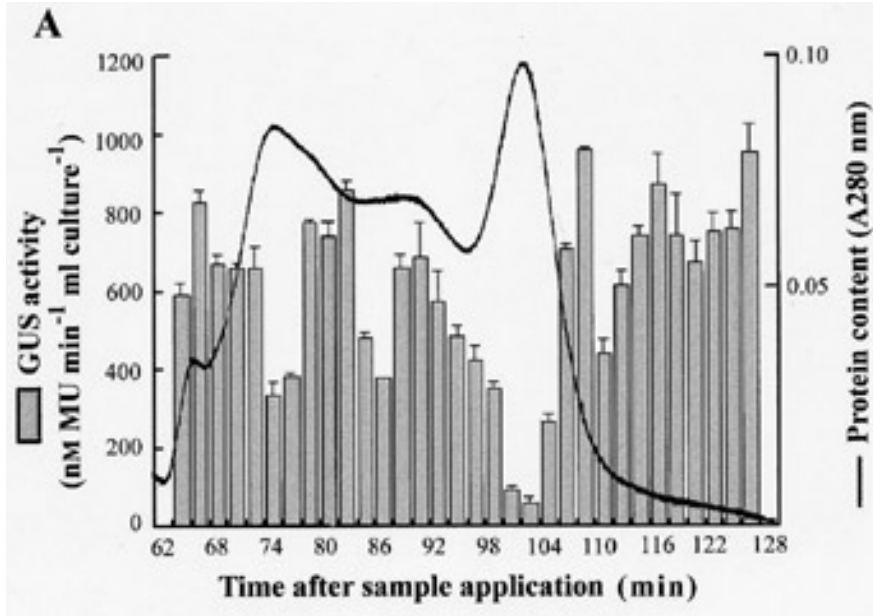

B
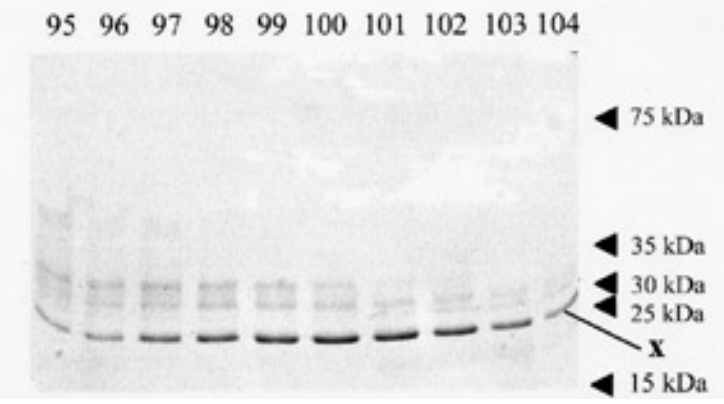

Fig. 4. Gel filtration chromatography ( 3 to $75 \mathrm{kDa}$ ) of the antifungal eluates resulting from $10-$ to $600-\mathrm{kDa}$ gel filtration chromatography of the $80 \%$ $\left(\mathrm{NH}_{4}\right)_{2} \mathrm{SO}_{4}$-saturated fraction from Arina seed extract. A, Gel filtration chromatography and growth of Fusarium culmorum (G514) in potato dextrose broth (PDB) containing the resulting eluates. Protein content was measured by absorbance at $280 \mathrm{~nm}$. Fungal biomass was measured and expressed as mean $\beta$-D-glucuronidase (GUS) activity (PDB $=753 \pm 47 \mathrm{nM}$ methylumbelliferyl $[\mathrm{MU}]$ per min per $\mathrm{ml}$ of culture). Bars indicate standard deviation. B, Sodium dodecyl sulfate-polyacrylamide gel electrophoresis of nonreduced proteinaceous compounds eluted between 90 and 108 (lanes 90 to 108, respectively) after sample application. Arrows indicate apparent molecular mass markers $(\mathrm{kDa})$ and marker $\mathrm{X}$ indicates position of a proteinaceous compound strongly associated with antifungal activity $(r=0.96)$. activity is indeed due to these compounds, both are interesting for different reasons. The $28-\mathrm{kDa}$ protein falls into the molecular mass range of many previously identified antifungal proteins such as chitinases, RIPs, permatins, and 1,3- $\beta$-glucanases, all of which have reported molecular masses $\leq 36 \mathrm{kDa}$. Chitinases range in size from 26 to $36 \mathrm{kDa}(1,5,21,24-26)$ and RIPs are proteins with molecular masses between 28 and $31 \mathrm{kDa}(2,5)$, while $1,3-\beta$-glucanases range in size from 21 to $31 \mathrm{kDa}(5)$. The $60-\mathrm{kDa}$ proteinaceous compound is interesting because the majority of antifungal proteinaceous compounds isolated, to date, from plant seeds are significantly smaller than $50 \mathrm{kDa}$.

Future work will focus on the further characterization of the antifungal compounds detected in Arina soluble seed extract and determine their role, if any, in the resistance of these cultivars to FHB. Also, the relationship, if any, between Arina seed and stem base antifungal activity will be further investigated. Ultimately, these antifungal fractions isolated from seed extracts could yield one or more potent antifungal proteinaceous compounds that will provide a basis from which to begin investigations into the mechanisms underlying Fusarium resistance in wheat.

\section{ACKNOWLEDGMENTS}

The work of the Cereals Research Department is supported by the Ministry of Agriculture, Fisheries, and Food. We thank A. J. Worland and J. K. M. Brown (John Innes Centre, United Kingdom), P. Wilson (Pioneer Hibred, United Kingdom), and $\mathrm{H}$. Beurstmayr (Institute for Agrobiotechnology, Austria) for providing wheat seed for this work. We also thank G. Weston and N. Gosman, John Innes Centre, United Kingdom, for their assistance.

\section{LITERATURE CITED}

1. Boller, T. 1985. Induction of hydrolases as a defense reaction against pathogens. Pages 247-262 in: Cellular and Molecular Biology of Plant Stress. J. L. Key and T. Kosuge, eds. Alan R. Liss Publishers, New York.

2. Buerstmayr, H. 1997. Genetic analysis of Fusarium head blight (scab) resistance in winter wheat by monosomic analysis. Ph.D. thesis. University of Agricultural Sciences, Vienna, Austria.

3. Buerstmayr, H., Lemmens, M., Grausgruber, H., and Ruckenbauer, P. 1996. Scab resistance of international wheat germplasm. Cereal Res. Commun. 24:195-202.

4. Chen, Z.-Y., Brown, R. L., Lax, A. R., Guo, B. Z., Cleveland, T. E., and Russin, J. S. 1998. Resistance to Aspergillus flavus in corn kernels is associated with a 14-kDa protein. Phytopathology 88:276-281.

5. Darnetty, Leslie, J. F., Muthukrishnan, S., Swegle, M., Vigers, A. J., and Selitrennikoff, C. P. 1993. Variability in antifungal proteins in the grains of maize, sorghum and wheat. Physiol. Plant. 88:339-349.

6. Dixon, R. A., and Harrison, M. 1990. Activation, structure and organization of genes involved in microbial defense in plants. Adv. Genet. 28:165-234.

7. Doohan, F. M., Smith, P., Parry, D. W., and Nicholson, P. 1999. Transformation of Fusarium culmorum with the $\beta$-D-glucuronidase (GUS) reporter gene: A system for studying host-pathogen relationships and disease control. Physiol. Mol. Plant Pathol. 53:253-268.

8. Grausgruber, H., Lemmens, M., Buerstmayr, H., and Ruckenbauer, P. 1998. Chromosomal location of Fusarium head blight resistance and in vitro toxin tolerance in wheat using the Hobbit 'sib' (Triticum macha) chromosome substitution lines. J. Genet. Breed. 53:173-180.

9. Guo, B. Z., Chen, Z.-Y., Brown, R. L., Lax, A. R., Cleveland, T. E., Russin, J. S., Metha, A. D., Selitrennikoff, C. P., and Widstrom, N. W. 1997. Germination induces accumulation of specific proteins and antifungal activities in corn kernels. Phytopathology 87:1174-1178.

10. Harris, E. L. V. 1993. Purification and concentration by precipitation. Pages 151-160 in: Protein Purification Methods: A Practical Approach. E. L. V. Harris and S. Angel, eds. Oxford University Press, Oxford.

11. Huang, Z., White, D. G., and Payne, G. A. 1997. Corn seed proteins inhibitory to Aspergillus flavus and aflatoxin biosynthesis. Phytopathology 87:622-627.

12. Ireta, M. J., and Gilchrist, S. 1994. Fusarium head blight scab of wheat (Fusarium graminearum Schwabe). Wheat Special Rep. No. 21b. CIMMYT, Mexico, D.F., Mexico.

13. Joffe, A. 1978. Fusarium poae and Fusarium sporotrichoides as principal causes of alimentary toxic aleukia. Pages 21-86 in: Handbook of Mycotoxins and Mycotoxicosis, Vol. 3. T. D. Wyllie and L. G. Morehouse, eds. Marcel Dekker, New York. 
14. Lamb, C. J., Lawton, M. A., Dron, M., and Dixon, R. A. 1989. Signals and transduction mechanisms for activation of plant defenses against microbial attack. Cell 56:215-224.

15. Marasas, W. F. O., Nelson, P. E., and Toussoun, T. A. 1984. Toxigenic Fusarium species: Identity and mycotoxicology. The Pennsylvania State University Press, University Park.

16. Mesterházy, A. 1987. Selection of head blight resistant wheats through improved seedling resistance. Plant Breed. 98:25-36.

17. Miedaner, T. 1997. Breeding wheat for resistance to Fusarium diseases. Plant Breed. 116:201-220.

18. Miller, J. D., and Arnison, P. G. 1986. Degradation of deoxynivalenol by suspension cultures of the Fusarium head blight resistant wheat cultivar Frontana. Can. J. Plant Pathol. 8:147-150.

19. Miller, J. D., Young, J. C., and Sampson, D. R. 1985. Deoxynivalenol and Fusarium head blight resistance in spring cereals. Phytopathol. Z. 113:359-367.

20. Parry, D. W., Jenkinson, P., and McLeod, L. 1995. Fusarium earblight (scab) in small grain cereals: A review. Plant Pathol. 44:207-238.

21. Pegg, G. F., and Young, D. H. 1982. Purification and characterization of chitinase enzymes from healthy and Verticillium albo-atrum infected tomato plants, and from V. albo-atrum. Physiol. Plant Pathol. 23:289-303.

22. Proctor, R. H., Hohn, T. M., and McCormick, S. P. 1995. Reduced virulence of Gibberella zeae caused by disruption of a trichothecene toxin biosynthetic gene. Mol. Plant-Microbe Interact. 8:593-601.

23. Roberts, W. K., Laue, B. E., and Selitrennikoff, C. P. 1988. Antifungal proteins from plants. Ann. N.Y. Acad. Sci. 544:141-151.

24. Roberts, W. K., and Selitrennikoff, C. P. 1986. Isolation and partial characterization of two antifungal proteins from barley. Biochim. Biophys. Acta 880:161-170.

25. Roberts, W. K., and Selitrennikoff, C. P. 1986. Plant proteins that inactivate foreign ribosomes. Biosci. Rep. 6:19-29.

26. Roberts, W. K., and Selitrennikoff, C. P. 1988. Plant and bacterial chitinases differ in antifungal activity. J. Gen. Microbiol. 134:169-176.

27. Roberts, W. K., and Selitrennikoff, C. P. 1990. Zeamatin, an antifungal protein from maize with membrane-permeabilizing activity. J. Gen. Microbiol. 136:1771-1778.

28. Schroeder, H. W., and Christensen, J. J. 1963. Factors affecting the resistance of wheat to scab caused by Gibberella zeae. Phytopathology 53:831-838.

29. Šíp, V., and Stuchlíková, E. 1997. Evaluation of the response of winter wheat varieties to artificial infection with Fusarium culmorum in field conditions. Cereal Res. Commun. 25:977-983.

30. Snedecor, G. W., and Cochran, W. G. 1980. Statistical Methods. The Iowa State University Press, Ames.

31. Snijders, C. H. A. 1990. Genetic variation for resistance to Fusarium headblight in bread wheat. Euphytica 50:171-179.

32. Snijders, C. H. A. 1990. Aspects of resistance to Fusarium head blight caused by Fusarium culmorum in wheat. Ph.D. thesis. Agricultural University, Wageningen, the Netherlands.

33. Ueno, Y. 1980. Trichothecene mycotoxins: Mycology, Chemistry and Toxicology. Pages 301-353 in: Advances in Nutritional Research, Vol. 3. H. H. Draper, ed. Plenum Publishing Corporation, New York.

34. Van Ginkel, M., Van Der Schaar, W., Zhuping, Y., and Rajaram, S. 1996. Inheritance of resistance to scab in two wheat cultivars from Brazil and China. Plant Dis. 80:863-867.

35. Vigers, A. J., Roberts, W. K., and Selitrennikoff, C. P. 1991. A new family of plant antifungal proteins. Mol. Plant-Microbe Interact. 4:315-323.

36. Vigers, A. J., Wiedemann, S., Roberts, W. K., Legrand, M., Selitrennikoff, C. P., and Fritig, B. 1992. Thaumatin-like proteins are antifungal. Plant Sci. 83:155-161.

37. Wang, Y. Z., and Miller, J. D. 1988. Effects of Fusarium graminearum metabolites on wheat tissue in relation to Fusarium head blight resistance. J. Phytopathol. 122:118-125.

38. Yu, Y. J. 1982. Monosomic analysis for scab resistance and yield components in wheat cultivar Soo-moo-3. Cereal Res. Commun. 10:185-190. 